IV without cross-references. A comprehensive index is promised as part of a final volume and it is probable that this will correct this defect, which is of considerable importance if the work is to be of the use the editor intends to workers not familiar with some of these fields.

Although these volumes appear to be of very comprehensive size it is clear that they can only be an outline of the vast ramifications of oncology today but they present a very well balanced summary of current work. Those readers whose main interest is in tumours can be expected to find much of fascinating interest while general medical readers who are not deterred by the austere black covers will, perhaps, be surprised at discovering a most readable and absorbing account of the many facets of this great medical problem.

\section{OCULAR ALLERGY}

By Frederick H. Theodore, M.D., and Abraham Schlossman, M.D. Pp. xviii +420 , with I I I illustrations. London: Ballière, Tindall and Cox Ltd. 1958. $96 \mathrm{~s}$.

This book is a welcome edition to the repertoire of ophthalmic textbooks. The authors have chosen their subject matter wisely and have filled a void in the ophthalmic literature. The importance of ocular allergy and the ocular manifestations of generalized allergy is increasing daily, particularly as more and more drugs used in the eyes become available.

These drugs are used not only by ophthalmologists, but also, in vast amounts, by general practitioners. Hence this is a work of importance not only to the oculist, but also to the medical student, the general practitioner and, because of the common ocular manifestations of generalized allergies, to the dermatologist. It is in this very respect, however, that the book is a trifle disappointing. It is crammed with facts, has an excellent bibliography, but the style of writing is tedious, the book is rather too long and too detailed for pleasant readingڤ Admittedly the subject is a difficult and exacting one; all the more reason for trying to make if palatable. Nevertheless, for the industrious it has an invaluable accumulation of facts and clinical material. It is the best reference on its subject. available and deserves the effort of careful studyo Furthermore, it is competently set out, well printe and beautifully illustrated.

The text contains a chapter devoted to the basiç principles of allergy before considering allergies of the eye. This chapter is brief, to the point and of great value to anyone not very well informed on the concept of allergy. It is, I think, the best chapter. The rest of the book is then devoted to allergies as they affect each region of the eye.

\section{SYMPOSIUM ON NUCLEAR SEX}

Edited by D. Robertson SMith, M.A., M.D., an William M. Davidson, M.D. Pp. xvii $+18 \%$ illustrated. London: William Heinemann Medi cal Books Ltd. 1958. 2 is.

This compact book with over 20 original articles is based on the Symposium on Nuclear Sex held as King's College Hospital Medical School in Sep? tember, 1957, and attended by Professor Murray Barr who, with E. G. Bertram, first drew attentiofs to a sex difference in resting nuclei, in the forsto instance in the neurones in cats. The articles are accompanied by illustrations including phofo micrographs and the exellent lists of references at the end of each have been brought up to date. There is a report of the discussions. The subjects covere range over studies of the sex chromatin in the intersexes and tumours, as well as the more funda $\overrightarrow{\overrightarrow{0}}$ mental relationship to the chromosomes.

The book is an excellent up-to-date survey the work in this field.

\section{NOTICE OF SPECIAL INTEREST TO SUBSCRIBERS:}

\author{
- WHY NOT HAVE YOUR COPIES OF THIS \\ JOURNAL BOUND INTO YEARLY VOLUMES?'
}

You can have your twelve monthly issues fully bound in dark green pin head cloth. lettered in gilt on spine with name of Journal, Volume Number and year, complete with index at front, for 22s. 6d. post free. A limited number of out of print journals are available to bind into volumes and make your library complete. Price on application giving details of issues required to complete back volumes.

THE
WHY NOT

HAVE YOUR JOURNALS BOUND? 